\title{
СОЦИАЛЬНЫЕ ВЫЗОВЫ ДЕМОГРАФИЧЕСКИХ ИЗМЕНЕНИЙ
}

\section{Лидия ТКАЧЕНКО ${ }^{\odot}$, кандидат экономических наук, старший научный сотрудник} Институт демографии и социальных исследований имени М.В. Птухи, Национальная академия наук Украины

DOI: https://doi.org/10.36004/nier.cdr.2019.14-03 JEL Classification: J11.

\begin{abstract}
Взаимосвязь между динамикой населения, экономическим ростом и сочиальным развитием всегда пребывает в цеентре внимания научных исследований. В современном мире все больше стран сталкиваются с сокращением населения трудоспособного возраста при одновременном увеличении численности пожильх людей. $C$ одной стороны, это ограничивает масштабы занятости и может замедлять рост производительности, $c$ другой стороны - усиливает давление на систему публичных финансов, требуя увеличения расходов на пенсии, здравоохранение и долговременный уход. Наиболее остро это проявляется в странах Восточной Европы, включая Украину и Молдову, где быстрые темпь депопуляции обусловлены не только низкой рождаемостью, но и отсутствием устойчивого роста ожидаемой продолжительности жизни. В этих условиях особенно важно рассматривать старение населения не как клубок проблем, а как систему вызовов, в которых нужно научиться находить стимуль $и$ возможности для развития. С использованием структурно-сравнительных и прогнозных методов, в статье оценивается влияние социальных вызовов демографических изменений и степень их учета в политических решениях.
\end{abstract}

Ключевые слова: демографические изменения, старение, сокращение населения, депопуляция, пенсионный возраст, рабочая сила, социальная политика.

The relationship between population dynamics, economic growth and social development has always been the focus of scientific research. In the modern world, more and more countries are facing a reduction in the working-age population while increasing the number of older people. On the one hand, this limits the scope of employment and can slow down productivity growth; on the other hand, it increases the pressure on public finances, requiring an increase in spending on pensions, healthcare, and long-term care. This is most acute in countries of Eastern Europe, including Ukraine and Moldova, where rapid depopulation is due not only to low birth rates, but also to the absence of a steady increase in life expectancy. In these conditions, it is especially important to consider aging not as a tangle of problems, but as a system of challenges, which contains a source of incentives and opportunities for development. Using structural, comparative and forecasting methods, the article assesses the impact of the social challenges of demographic changes and the degree to which they are taken into account in political decisions.

Key words: demographic changes, ageing, population decline, depopulation, retirement age, labour force, social policy.

Терминология и общие теоретические подходы. Демографическими изменениями принято называть динамические сдвиги в численности и структуре населения. Обычно подразумевается, что эти сдвиги происходят в процессе демографического перехода от традиционного к современному типу воспроизводства, хотя на практике термин «демографические изменения» также широко применяется как самостоятельный и универсальный. Частично это связано с многоликостью самого процесса демографического перехода: разные страны/регионы присоединились к нему в разное время, двигались с разной

\footnotetext{
๑ Лидия Ткаченко, lidiia1tkachenko@gmail.com
} 
скоростью и находятся на разных этапах; существуют также различные мнения относительно общего количества, последовательности этапов перехода и признаков ожидаемого «финиша». Действительно универсальный характер термина «демографические изменения» объясняется тем, что его одинаково удобно применять как для анализа прошлых событий, так и для очертаний будущего, как для целых исторических эпох, так и для совсем коротких отрезков времени. Он лишен эмоциональной окраски и применим ко всем составляющим демографического движения, независимо от направления тенденции или ее отсутствия. Но главное, что он акцентирует внимание на внешней объективности движения населения, подчеркивая необходимость его учета во всех сферах политики.

Взаимосвязь между динамикой населения, экономическим ростом и социальным развитием всегда был предметом экономической науки. Одним из первых этот вопрос теоретически рассматривал Т. Мальтус, который в конце XVIII века сформулировал свой знаменитый закон народонаселения [10]. Почти на целых два века мальтузианский закон стал основой для построения моделей, которые с разной степенью детализации вычисляли, при какой численности населения экономический рост становится невозможным и сколько людей могут погибнуть от голода вследствие перенаселения. Во второй половине ХХ столетия все большее распространение стали получать неоклассические теории, которые доказывали, что увеличение населения может сосуществовать с ростом реального ВВП на душу населения за счет технического прогресса и усиление институциональных механизмов. Самые большие оптимисты обосновывали, что быстрое увеличение населения может оказывать положительное влияние на экономический рост, а большие общества имеют лучшие возможности для развития благодаря эффекту масштаба [3].

Сейчас, когда все большее количество стран сталкиваются с сокращением населения трудоспособного возраста при одновременном увеличении населения пенсионного возраста, дискуссии вокруг роли населения в процессе экономического роста приобретают совершенно противоположную направленность, чем во времена классического мальтузианства. Старение населения становится самым большим вызовом для возможностей экономического роста и человеческого развития, поскольку, с одной стороны, лимитирует прирост масштабов занятости, замедляет рост производительности, с другой - усиливает давление на систему публичных финансов, требуя увеличения расходов на пенсии, здравоохранение и долговременный уход [1].

Особенности демографических изменений в Украине. Демографические изменения, происходящие в Украине, имеют глобальный характер и в той или иной степени касаются большинства стран региона. Однако в Украине они приобретают особо драматическое звучание, достигая пиковых значений по скорости и глубине.

По оценкам ООН, Украина входит в пятерку стран мира с самыми высокими темпами сокращения населения - не менее чем на 20\% к 2050 г. [8]. Если в 1950 г. Украина с 37 млн населения занимала 15-е место в рейтинге из 21 крупнейших стран мира, то в 2019 г. с 44 млн (с учетом Крыма) не вошла даже в тридцатку. По среднему варианту прогноза ООН, численность населения Украины в 2050 г. составит 35,2 млн. То есть к 2050 г. наша страна «вернется» к показателю 1950 г., но по меркам нового мира будет считаться уже скорее маленькой страной.

Быстрые темпы депопуляции в Украине обусловлены не только низкой рождаемостью, но и отсутствием устойчивого прогресса в показателях ожидаемой продолжительности жизни. По оценкам ООН, Украина вместе с Молдовой и Российской Федерацией имеют самые низкие показатели ожидаемой продолжительности жизни в Европе (в среднем 72 года при рождении), отставая от стран Западной, Южной и Северной Европы на целых 10 лет [8].

Депопуляцию углубляют значительные разрывы в возрастной структуре населения, которые стали следствием резких колебаний уровней рождаемости и смертности в годы 
социальных потрясений (войны, кризисы), нарушивших нормальный ход демографического развития страны. Резкий спад рождаемости в 1990-х - начале 2000-х привел к тому, что нынешние поколения молодежи, которые вступают во взрослую жизнь и выходят на рынок труда, по численности значительно (чуть ли не в два раза) уступают старшим поколениям, достигающим пенсионного возраста. Такое наложение демографических волн ведет к новому витку в процессе старения.

По среднему варианту демографического прогноза ООН, в период до 2050 г. население Украины сократится на 8,5 млн человек, причем население 20-59 лет (фактические границы экономически активного возраста) уменьшится на 7,8 млн или на $32 \%$, тогда как население в возрасте 60 лет и старше увеличится на 1,6 млн человек или на $16 \%$ (Таблица 1.). Доля людей в возрасте 60 лет и старше в общей численности населения возрастет с $24 \%$ до $34 \%$, а соотношение возрастных контингентов 20-59 лет и $60+$ уменьшится с 2,4 до 1,4.

\section{Таблица 1. Ожидаемая динамика населения Украины в разрезе возрастных групп}

\begin{tabular}{|l|c|c|c|c|}
\hline Показатели & Всего & 0-19 лет & $\mathbf{2 0 - 5 9 ~ л е т ~}$ & 60+ лет \\
\hline Численность в 2020 г., млн & 43,7 & 9,0 & 24,4 & 10,3 \\
\hline Численность в 2050 г., млн & 35,2 & 6,7 & 16,5 & 12,0 \\
\hline Изменение численности за 2020-2050 гг.: \\
\hline в млн человек & $-8,5$ & $-2,3$ & $-7,8$ & 1,6 \\
\hline в \% & $-19 \%$ & $-26 \%$ & $-32 \%$ & $16 \%$ \\
\hline Удельный вес в 2020 г., \% & $100 \%$ & $21 \%$ & $56 \%$ & $24 \%$ \\
\hline Удельный вес в 2050 г., \% & $100 \%$ & $19 \%$ & $47 \%$ & $34 \%$ \\
\hline
\end{tabular}

Источник: Расчеты автора по данным [9]

Ожидаемое сокращение населения экономически активного возраста на $32 \%$ с одновременным увеличением населения пенсионного возраста на $16 \%$ представляет огромный вызов для перспектив развития, особенно с учетом, что в Украине уже сейчас чувствуется дефицит рабочей силы, а пенсионная система имеет хронический дефицит.

Возможные пути уменьшения рисков. Зарубежные исследователи выражают оптимизм, что в странах, не достигших высокого индустриального развития, существуют значительные резервы для экономического роста даже в условиях сокращения населения [3]. Ситуацию помогут исправить такие меры:

- стимулирование экономической активности ранее недостаточно привлеченных слоев населения (учащаяся молодежь, женщины, люди старшего возраста, люди с инвалидностью, мигранты и др.);

- внедрение современных технологий;

- укрепление институциональной поддержки;

- инвестиции в накопление человеческого капитала, научные разработки и инновации;

- перераспределение занятости из традиционного сельского хозяйства и других низкодоходных секторов экономики в сектора с более высокой добавленной стоимостью.

Bce эти направления, в любом случае, являются составляющими общего эволюционного прогресса, но в условиях быстрых демографических изменений их темп может оказаться недостаточным. Для мобилизации резервов роста нужна целенаправленная, комплексная, взвешенная политика, что, к сожалению, нехарактерно для наших стран.

В контексте демографических изменений, уровень адекватности национальной политики можно измерять по отношению к повышению пенсионного возраста.

Например, страны Северной и Западной Европы в числе первых инициировали повышение пенсионного возраста, хотя ситуация у них не самая критическая. Эти страны 
давно ступили на путь демографического перехода и высокий уровень старения у них связан с достижением очень высоких показателей продолжительности жизни. По сравнению со среднеевропейскими показателями, они имеют достаточно высокий уровень рождаемости, и им удается поддерживать стабильные темпы естественного прироста (за исключением Германии) [8]. Эти страны имеют также очень высокие уровни занятости по всем группам населения, включая женщин и людей старшего возраста, что обеспечивается диверсифицированной экономикой и развитой занятостью в сфере услуг [2]. Хотя демографическая ситуация, уровень занятости и доходов в целом благоприятны для финансового самочувствия пенсионной системы, в большинстве этих стран пенсионный возраст уже достиг порога 65 лет (причем как для мужчин, так и для женщин), и речь уже идет о дальнейшем повышении до 67 лет и далее. Исключение составляет лишь Франция, где пенсионный возраст долгое время оставался на уровне 60 лет, и пока решение принято о повышении только до 62 лет [6].

Страны Южной Европы также имеют высокий уровень старения и высокую продолжительность жизни. Но, в отличие от стран Северной и Западной Европы, у них сверхнизкая рождаемость и значительно более низкие уровни занятости населения, особенно среди женщин и людей старшего возраста. Экономика этих стран менее диверсифицирована, в частности остается относительно большая доля занятости в аграрном и торговом секторах. Несмотря на все эти обстоятельства, политики этих стран долгое время пытались избегать пенсионных реформ. Решение о повышении пенсионного возраста были приняты ими в условиях жесткого финансово-экономического кризиса, на фоне рекордно высоких показателей безработицы, под сильным внешним давлением и в пакете с многочисленными мероприятиями по урезанию социальных благ, что обусловило крайне негативное восприятие реформы.

Политика в Украине. В Украине с октября 2011 г. началось постепенное (на полгода ежегодно) повышение пенсионного возраста для женщин. В 2021 г. пенсионный возраст женщин достигнет 60 лет и сравняется с показателем для мужчин. Уже сейчас совершенно ясно, что 60 лет - это неприемлемо мало с учетом демографических перспектив Украины и показателей в других странах мира, не только Европы.

Тем не менее, украинские политики пытаются держать табу на дальнейшее повышение пенсионного возраста. Пенсионная реформа 2017 г. прошла под лозунгом «зато мы не повышаем пенсионный возраст». В поисках других способов ограничения притока новых пенсионеров, ставка была сделана на усиление требований к страховому стажу, дающего право на назначение пенсии по старости. Так называемый «коридор» пенсионного возраста предполагает, что возраст назначения пенсии по старости будет определяться по критериям стажа. Будет три возрастных порога - 60/63/65 лет, причем критерии стажа будут постепенно повышаться в течение 10 лет, начиная с 2018 г. В 2028 г. выйти на пенсию в 60 лет смогут люди со стажем не менее 35 лет, в 63 года - со стажем от 25 до 35 лет, в 65 лет со стажем от 15 до 25 лет.

Привязка права на пенсию к длительности стажа, конечно, должна способствовать повышению эффективного пенсионного возраста, то есть фактического возраста назначения пенсии по старости. Однако такой непрямой путь имеет уязвимости.

Во-первых, стаж менее объективный показатель, чем возраст, в частности очень сильно влияют изменения в правилах учета стажа. В Украине есть значительные особенности по учету стажа до и после введения системы персонификации (введена с 1 июля 2000 г.). До 2000 г. страховой стаж засчитывается по записям в трудовой книжке и другим подобным документам, после 2000 г. - по данным системы персонификации об уплате взносов, причем за каждый месяц уплаченный взнос должен быть не меньше минимального, иначе стаж пропорционально уменьшается. Кроме того, в стаж до 2000 г. засчитывается период обучения в профессиональных учебных заведениях. Есть также различия по учету и 
длительности кредитных периодов, которые засчитываются в стаж без уплаты взносов (срочная военная служба, отпуск по уходу за ребенком и т.п.).

Во-вторых, вся ответственность за (не)приобретение стажа возлагается на человека, хотя люди далеко не всегда имеют возможность выбирать рабочее место. В распространении неформальной занятости есть значительная вина государства, которое фактически провалило реформы переходного периода и самоустранилось от надзора за соблюдением трудового законодательства. Если говорить о нынешних молодых людях, учитывая растущую продолжительность обучения, они просто не успеют заработать 35 лет стажа до достижения 60-летнего возраста. Установление недостижимых критериев может привести к еще большему разочарованию относительно участия в системе пенсионного страхования.

B-третьих, выход на пенсию в 60 лет преподносится как бонусное вознаграждение, а на самом деле более ранний выход на пенсию означает более длительный период экономически неактивной жизни и повышенные риски бедности, особенно для женщин.

В-четвертых, официально пенсионный возраст остается 60 лет, и по достижении этого возраста любое лицо может претендовать на пособие малообеспеченным в размере, равном минимальной пенсии по старости. Таким образом, уменьшение численности пенсионеров и/или расходов на страховые пенсии по возрасту может обернуться увеличением численности малообеспеченных и расходов на различные государственные социальные пособия. При этом существенно увеличиваются риски бедности для людей пенсионного возраста.

Доминирование однозначно негативного отношения к теме повышения пенсионного возраста связано с общим восприятием реформы как ограничения прав, конкретно как намерения сэкономить на выплате пенсий. Однако такое представление не является верным: специалисты утверждают, что для пенсионной системы повышение пенсионного возраста имеет актуарно нулевой эффект [4]. Повышение пенсионного возраста дает возможность сократить количество новых назначений пенсий, но лишь на некоторое время. Когда новый порог пенсионного возраста достигнут, поколения уходят на пенсию в полном составе и «экономия» на новых пенсионерах исчезает, а общее количество пенсионеров по старости может снова начать расти. Новые пенсионеры также не теряют своих прав: более высокий порог пенсионного возраста стимулирует дольше работать и при прочих равных условиях они успеют заработать себе больший стаж и более высокие пенсии. Таким образом, повышение пенсионного возраста не ведет к снижению размера выплат, наоборот, способствует их росту, как у нынешних, так и у будущих поколений пенсионеров.

В контексте демографических изменений, нужно научиться видеть в этой реформе не ограничение, а стимулы и возможности. Повышение пенсионного возраста следует рассматривать, прежде всего, с позиций расширения возможностей занятости, увеличения шансов личностной самореализации в трудовой карьере и улучшения материального благосостояния. Хотя национальные законодательства, как правило, не допускают прямых запретов на занятость пенсионеров, существует множество официальных правил и негласных практик, которые значительно ограничивают стимулы и гарантии занятости после назначения пенсии. Например, многие страны сокращают выплаты работающим пенсионерам пропорционально рабочему времени, размеру пенсии или размеру заработка/совокупного дохода [6]. Удержаться на «хорошей» должности в статусе пенсионера гораздо труднее, негласные дискриминационные практики приводят к сегрегации работающих пенсионеров в низкооплачиваемых и «непрестижных» профессиях/секторах экономики.

Повышение пенсионного возраста дает возможность поддержать пропорции между продолжительностью трудового и пенсионного периодов жизни - на уровне отдельного человека, и между численностью пенсионеров и населения трудоспособного возраста - на макроуровне. Это дает возможность оздоровить публичные финансы и повысить 
устойчивость пенсионной системы, обеспечить более высокий уровень пенсий без увеличения пенсионных расходов по отношению к ВВП. Сегодняшнее плачевное состояние пенсионной системы Украины является ярким свидетельством того, что экстенсивное распространение пенсионных прав на большое количество нестарых людей - прямой путь к снижению уровня доходов людей действительно пожилого возраста [6].

В условиях сокращения контингентов трудоспособного возраста и снижения предложения на рынке труда с соответствующими негативными последствиями для возможностей экономического роста, повышение производительности, качества труда и уровня участия в рабочей силе становятся решающими факторами экономического роста и человеческого развития [5]. В этом контексте повышение пенсионного возраста может и должно стать катализатором многих связанных экономических и социальных реформ, имеющих целью структурную перестройку экономики и рабочих мест, улучшение условий труда, реальное внедрение обучения в течение всей жизни, создание надлежащей инфраструктуры.

\section{Библиография}

1. Europe's demographic future: Facts and figures on challenges and opportunities. Luxembourg: Office for Official Publications of the European Communities, 2007, 177 p.

2. Eurostat (lfsi_emp_a). https://ec.europa.eu/eurostat/web/lfs/data/database\#.

3. Fotakis Constantinos, Peschner Jörg. Demographic change, human resources constraints and economic growth. The EU challenge compared to other global players. Working Paper 1/2015, Luxembourg: Publications Office of the European Union, 2015, 68 p.

4. Nerlich Carolin, Schroth Joachim. The economic impact of population ageing and pension reforms, ECB Economic Bulletin, 2018, Issue 2.

5. Schwarz Anita M., Omar S. Arias. The Inverting Pyramid: Pension Systems Facing Demographic Challenges in Europe and Central Asia. World Bank, Washington, 2014. DC. DOI: 10.1596/978-0-8213-9908-8.

6. The MISSOC comparative tables, 2019. https://www.missoc.org/missocdatabase/comparative-tables/.

7. Tkachenko Lidia. Rentenreform in der Ukraine. Friedrich-Ebert-Stiftung, Regionalbüro Ukraine \& Belarus. Kiew, Januar 2018, 44 s. http://library.fes.de/pdffiles/bueros/ukraine/14100.pdf.

8. United Nations, Department of Economic and Social Affairs, Population Division, 2019. World Population Prospects 2019: Highlights. ST/ESA/SER.A/423. https://population.un.org/wpp/Publications/Files/WPP2019_Highlights.pdf.

9. United Nations, Department of Economic and Social Affairs, Population Division. World Population Prospects 2019, Online $\quad$ Edition. https://population.un.org/wpp/Download/Files/1_Indicators\%20(Standard)/EXCEL_FILES/1_Popu lation/WPP2019_POP_F08_1_TOTAL_POPULATION_BY_BROAD_AGE_GROUP_BOTH_SE $\underline{\text { XES.xlsx. }}$

10. Мальтус Т. Опыт о законе народонаселения. Антология экономической классики. М.: МП «ЭКОНОВ», «КЛЮЧ», 1993, с. 5-136. 